\title{
Promoting the Use of Social Commerce on SME in the Context of Logistics: UTAUT Model Examination
}

\author{
Zakky Zamrudi ${ }^{*}$ and Teguh Wicaksono ${ }^{1}$ \\ ${ }^{1}$ Islamic University of Kalimantan, Department of Management, Indonesia, Email: \\ jzakky@gmail.com,teguh.uniska@gmail.com
}

*Corresponding Author: Zakky Zamrudi

\begin{abstract}
Small and Medium Enterprises (SME's) was proven to increase the country economic condition due to its capability to retain the product and capital flow stay inside. SME's tend to be more creative than the large and traditional enterprises, though the profitability may vary across segment. The rise of technology has brought the customer to be more educated related to product due the ease of information dissemination. Web 2.0 was the basic of today's social media communication in the context of logistics, enabling the society to directly interconnected one to another. Based on this reason, this study proposed an alternative to understand the SME's owner in adopting the use of social media for business and logistics purposes including marketing, sales, product announcement, etc. This study involved 53 respondent around south east Kalimantan. The data was analyzed by using GSCA analysis due to its ability to explore the effect amongst variable while ensuring the consistencies. The results present that all exogenous variables show a positive and significant effect, though the only variable showing non-significant effect is the performance expectancies. The greatest effect is shown by the social factor on attitude towards the social commerce.
\end{abstract}

Keywords: GSCA, information technology, logistics, social media, social networking sites

\section{Introduction}

The popularity of social media has grown as a communication alternative in the era of digital society. This allows people to join virtual communication through social networking sites (SNS) or better known as social media. Social media has grown from personal communication to business and logistics services interactions for commercial purposes which became known as social commerce (s-commerce). The term "social commerce" was first introduced in 2005 by Yahoo! [1]. Social commerce defined as a new stream of e-commerce that allows consumers to take action in producing content [2-5]. Kim \& Park (2013), describe s-commerce as combining e-commerce with 
social media. Hargadon \& Bechky (2006), state that s-commerce will enable vendors to reach different markets by integrating consumer social interactions.

S-commerce emerges as a corporate marketing strategy tools to promote the latest products, provided services and any related information. Social-commerce could be used as a collaborative media with customers to share their online shopping experiences and any information related to products or logistics services provided by the company [6]. According to Hoelzel (2004), about \$ 8.5 billion the corporate cost was spent on social networking sites in 2014 and will reach nearly \$ 14 billion in 2018. The data of online buying and selling transactions in Indonesia in 2014 was recorded at 34.9 trillion rupiahs (Bank of Indonesia, 2016). This fact shows a potential market share for the SME's in the future.

The high level of competition requires the SME owners to continue to innovate, one of which is through the renewal of marketing strategy employing the social media namely s-commerce. Parrott et al., (2010) suggested that one of the reasons for using s-commerce is because the SME marketing strategy planning model is more flexible and less dizzy with complicated planning. The finding of recent studies also indicates to implement the technology-entrepreneurship [7-9].

The importance of s-commerce in current situation has brought this study to find out any potential adoption of s-commerce in SMEs. The output of this study is expected to identify any potential factor behind the adoption of s-commerce in Sasirangan SME's. Furthermore, the studies are expected to promote an appropriate strategy in supporting the use of social commerce in the context of logistics services amongst the SME's.

To find out the potential adoption of s-commerce, the study used the technology acceptance framework known as the Unified Theory of Acceptance and Use of Technology (UTAUT) which was introduced by Venkatesh in 2003. It suggested that UTAUT could filter any related critical factors to predict behavioral intentions to use technology and technology use, especially in organizational contexts $[10,11]$.

The main purpose if this study is to examine the most affecting factors in adopting social commerce in the context of logistics by using social media which the model was developed by using UTAUT model. Most of current studies emphasize the use of e-commerce and rather limited in discussing the newly emerged social commerce [1]. Furthermore the use of social commerce was mostly anticipated from the standpoint of end user (customer). Most of studies have relied on the role of trust among end-users in pursuing the merchant validity. Moreover, this study was conducted on the specific area of SME's that produce fabric namely "Sasirangan" towards their intention to use social commerce. 
The rise of social media has recently becoming a popular topic. The recent studies have been mostly conducted on consumer sides and less taking on the business owners' side. Hajli et al , 2013 measures the consumer trust on social media and their implication on the trust amongst the social media user. Moreover, the study on SME's was limited related to the social commerce. The existing research was mostly focusing on a wider area of information technology issues such as the ecommerce on web 1.0 [12-14].

This research framework was built on the recent model mostly used to measure the adoption of ecommerce by using Unified Theory of Acceptance and Use of Technology (UTAUT). The recent study find that the low adoption of e-commerce was occurred due to the low trust on e-commerce performance on SME's. This research emphasizes most of the SME owners was having low ability to reach the e commerce which reflected by the variable of performance expectancy and entrepreneurial expectation $[15,16]$. According to recent studies the most relevant factor affecting the adoption of social commerce was the social factor and facilitating condition $[15,17]$.

Intention to use social commerce was derived from the technology acceptance model (TAM), that has been successfully predicting an individual intention to adopt a certain information systems [18]. Another related theory was the theory of planned behavior (TPB) by Ajzen in 1989. Intention to adopt social commerce was defined as the SME's entrepreneur to engage in social media not as a sole social media end user but rather act as a fan-page merchant [14].

The study stated above was also indicates the positive and significant indirect effect of the four construct namely performance expectancy, entrepreneurial expectancy, social factor, and facilitating condition.

\section{Data and Methods}

This study was a cross-sectional study which used the explanatory method by quantitative in nature. The purpose of the study was to predict the strongest factor in implementing the use of social commerce in heritage-product based SME's in South East Kalimantan, Indonesia.

\subsection{Instrument Development}

The research has six logistics-based constructs: intention to use social commerce, attitude towards behavior, performance expectancy, effort expectancy, social factor, and facilitating condition. The questionnaire was developed borrowing the Unified Theory of Acceptance and Used of Technology combined with related studies in technology implementation in SME's resulting 6 variable that consist of 22 questions. The questionnaire was measured by using 5 point Likert scale span from total disagree (1), disagree (2), neutral (3), agree (4), and totally agree (5). The dependent variable 
on this research was the intention to use/adopt social commerce which measures the SME's entrepreneur to pay more on social media and their intention to promote their product through social media.

\subsection{Data Collection}

The data was collected through a survey conducted in the south east Kalimantan province Indonesia during January to March. Before the main survey was conducted, a pilot studies were developed involving 25 SME's to ensure the wording and were clearly understood by the respondent. A total 98 questionnaire spread both in direct visit or sent via email. Due to the time limitation, the survey was end on March resulting 53 completed questionnaire were selected. The sample was drawn by using simple random sampling. The data was collected by using survey method by using questionnaire.

\subsection{Data Analysis}

The data was analyzed by using the Generalized Structured Component Analysis (GSCA) by the help of GesCA software. The method was employed due to the research purposes to explore the related model while ensuring the model consistency [19]. GSCA was the great alternative between the Covariance Based SEM (CB-SEM) with its ability to measure degree of model consistency (parametric capability) and Partial Least Square based SEM (PLS-SEM) with its ability to create a non-parametric capability for model assessment [20,21]. Thus this research was used GSCA as the alternative for both SEM modelling or called as semi-parametric SEM analysis. The steps on GSCA were including construct development, data gathering, model fit evaluation, outer model description, inner model (path analysis) amongst construct, and results discussions.

\section{Results}

This study was analyzed by using Generalized Structured Component analysis. According to the GesCa Software running the model was analyzed by using three steps consist of Model Fit evaluation, Outer Model evaluation and inner path model that used for hypothesis testing. According to the FIT and AFIT criteria, the proposed model is able to explain the variance for 0.639 .

The unweighted least square indicates by GFI and SRMR also shows a good results shows by the GFI 0.981 (close to 1 is better) and SRMR 0.271 (close to 0 is better). Based on these results, the proposed model has a good FIT model. 
Table 1 Model FIT Evaluation. Source: GesCa (2018)

\begin{tabular}{cc}
\hline \multicolumn{2}{c}{ Model Fit } \\
\hline FIT & 0.639 \\
\hline AFIT & 0.618 \\
\hline GFI & 0.987 \\
\hline SRMR & 0.271 \\
\hline
\end{tabular}

The outer model in this research was measured in order to shows the variance explained by the items evaluated and indicates the most important indicator corresponding to the latent variable. According to table 2 below, all the variables show the AVE value larger than 0.7. However the largest AVE was shows by the behavioral intention for 0.796. This means that the three items of BI1, BI2, BI3 are able to explain the intention to use social commerce for $79 \%$ which the other $21 \%$ were explained by other variable excluded in this research.

Table 2 Outer Model. Source: GesCa, 2018

\begin{tabular}{|c|c|c|c|c|c|}
\hline \multirow{2}{*}{$\begin{array}{c}\text { Variable/ } \\
\text { Items } \\
\end{array}$} & \multicolumn{3}{|c|}{ Loading } & \multirow[b]{2}{*}{ AVE } & \multirow[b]{2}{*}{ ALPHA } \\
\hline & Estimate & SE & $\mathbf{C R}$ & & \\
\hline \multicolumn{4}{|c|}{ Performance Expectancy } & 0.704 & 0.858 \\
\hline PE1 & 0.612 & 0.032 & $27.27^{*}$ & & \\
\hline PE2 & 0.576 & 0,076 & $7.62^{*}$ & & \\
\hline PE3 & 0.533 & 0,085 & $6.24^{*}$ & & \\
\hline PE4 & 0.606 & 0.037 & $23.41^{*}$ & & \\
\hline \multicolumn{4}{|c|}{ Entrepreneurial Expectancy } & 0.793 & .867 \\
\hline EE1 & 0.656 & 0.017 & $55.09^{*}$ & & \\
\hline EE2 & 0.638 & 0.041 & $22.41^{*}$ & & \\
\hline EE3 & 0.557 & 0.058 & $13.86^{*}$ & & \\
\hline \multicolumn{4}{|c|}{ Social Factor } & 0.749 & 0.705 \\
\hline SF1 & 0.620 & 0.040 & $22.12^{*}$ & & \\
\hline SF2 & 0.619 & 0,164 & $15.80^{*}$ & & \\
\hline SF3 & 0.561 & 0.063 & $12.73^{*}$ & & \\
\hline SF4 & 0.470 & 0,085 & $5.57^{*}$ & & \\
\hline \multicolumn{4}{|c|}{ Facilitating Condition } & 0.749 & 0.739 \\
\hline FC1 & 0.576 & 0.045 & $18.34^{*}$ & & \\
\hline FC2 & 0.567 & 0.050 & $16.42^{*}$ & & \\
\hline FC3 & 0.447 & 0.090 & $7.13^{*}$ & & \\
\hline FC4 & 0.438 & 0,142 & $3.09^{*}$ & & \\
\hline FC5 & 0.387 & 0,138 & $2.8^{*}$ & & \\
\hline \multicolumn{4}{|c|}{ Attitude Towards Behavior } & 0.745 & 0.821 \\
\hline ATT1 & 0.524 & 0,114 & $4.61^{*}$ & & \\
\hline ATT2 & 0.619 & 0.037 & $24.31^{*}$ & & \\
\hline ATT3 & 0.647 & 0.024 & $38.17^{*}$ & & \\
\hline \multicolumn{4}{|c|}{ Behavioral Intention } & 0.796 & 0.872 \\
\hline BI1 & 0.608 & 0.042 & $21.07^{*}$ & & \\
\hline BI2 & 0.630 & 0.024 & $38.15^{*}$ & & \\
\hline BI3 & 0.621 & 0.047 & $18.99^{*}$ & & \\
\hline
\end{tabular}


The outer loading of performance expectancy was mostly seen by item PE1, entreneurial expectancy was mostly seen by item EE1, variable of social factor was mostly seen by item SF1, variable facilitating condition was mostly seen by item FC1, Attitude towards behavior was mostly seen by item ATT3, and Behavioral intention was mostly seen by item BI2. Alpha in table 2 below shows the reliability of construct to measure the construct consistency amongst involved respondent. All of 6 variables shows a great results of reliability assessment shows by the value higher than 0.68 .

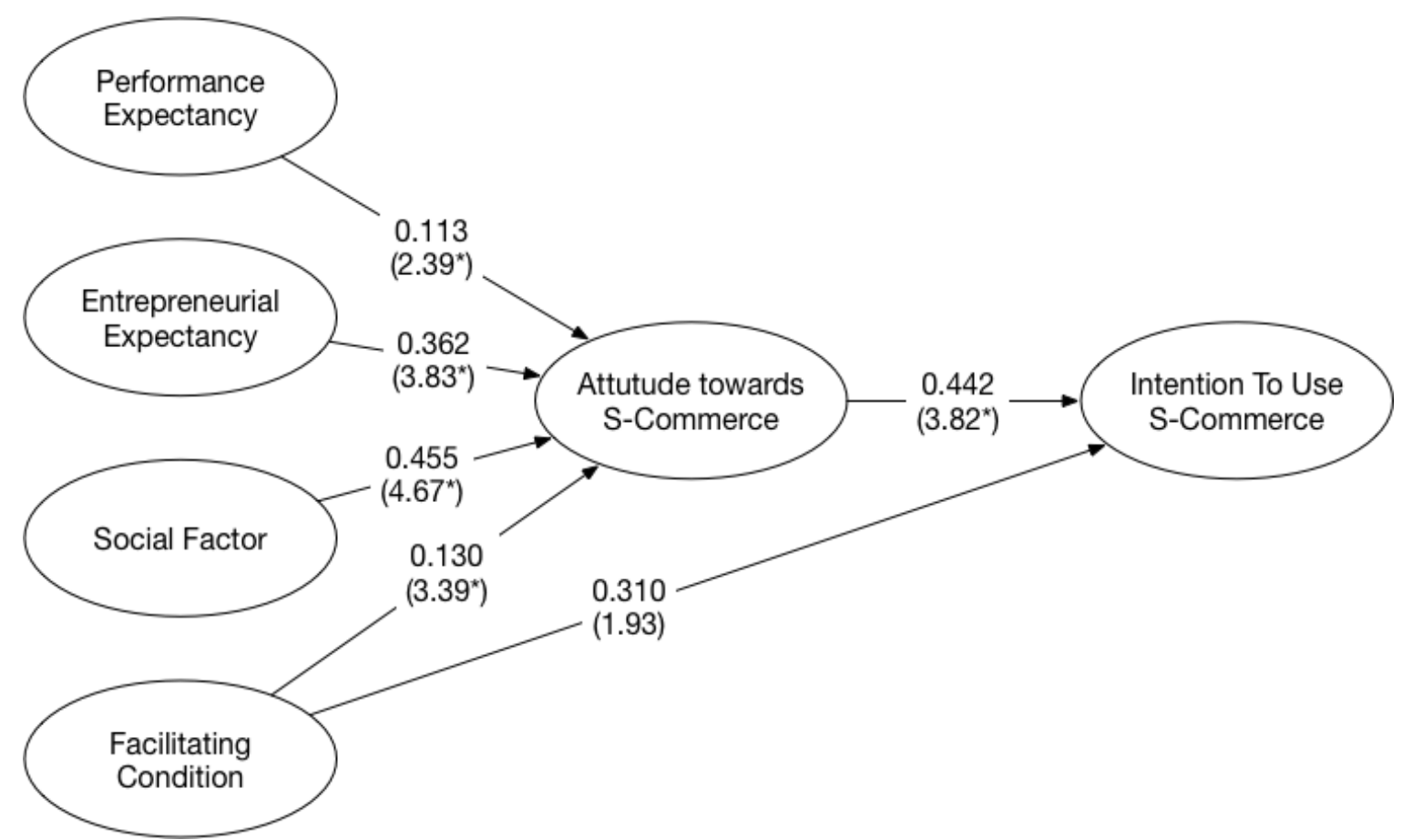

Fig. 1 UTAUT Inner Model Evaluation. Source: GesCA, 2018

Figure 1 below indicates the direct effect of endogen variable on exogenous variable. This validated model shows that performance expectancy, entrepreneurial expectancy, social factor, and have a significant effect on attitude towards social commerce. The largest loading factor was the social factor, that sequentially followed by entrepreneurial expectancy, facilitating condition and performance expectancy.

Yet, the model shows that the only variable that shows a non-significant effect on intention to use social commerce is facilitating condition. However, the indirect effect shown on table 2 below indicates that all the endogenous variables have a positive effect on intention to use social commerce in the context of logistics. The largest indirect effect was shown by the effect of social factor on intention to use social commerce mediated by attitude towards social commerce while it has a higher effect. 
Table 2 Inner Model. Source: Gesca \& Sobel Calculation, 2018

\begin{tabular}{lccccccc}
\hline \multicolumn{3}{c}{ Direct Path Coefficients } & \multicolumn{5}{c}{ Indirect Path Coefficient } \\
\hline & $\begin{array}{c}\text { Estima } \\
\text { te }\end{array}$ & SE & CR & & Estimates & SE & CR \\
\hline PE->ATT & 0.113 & 0.201 & $2.39^{*}$ & PE->ATT-> BI & 0.048 & 0.085 & $2.03^{*}$ \\
\hline EE->ATT & 0.362 & 0.138 & $3.83^{*}$ & EE->ATT->BI & 0.153 & 0.063 & $2.17^{*}$ \\
\hline SF->ATT & 0.455 & 0.118 & $4.67^{*}$ & SF->ATT->BI & 0.192 & 0.061 & $3,17^{*}$ \\
\hline FC->ATT & 0.130 & 0.232 & $3.39^{*}$ & FC->ATT >BI & 0.055 & 0.052 & $2.49^{*}$ \\
\hline FC->BI & 0.310 & 0.111 & 1.93 & & & & \\
\hline ATT->BI & 0.422 & 0.076 & $3.82^{*}$ & & & & \\
\hline
\end{tabular}

\section{Discussion}

The findings in this research suggest that the use of social commerce in the context of logistics has become an important alternative to the personalized websites as marketing tools. The use of social media as tools to promote products or logistics services are expected to help the local SME's entrepreneur to civilized their products/services across the island or even overseas. This study suggests that the most affecting aspect in implementing social commerce was the social factor both directly to the attitude towards the social commerce and indirectly to the intention to use social commerce. This means that the social condition around the SME's owner has a positive perception on social commerce resulting in a positive intention to adopt social commerce. Reviewing the results above, the only hypothesis that shows a non-significant effect was the facilitating condition on intention to use social commerce. This condition was consistent with the outer model assessment of facilitating condition that shows a small portion of items loading factor which mostly lies under 0.5. It can be summarized that the available IT infrastructure already reaching an equitable development resulting in the further advancement will not create a greater change towards the attitude towards social commerce.

This research suggests that the role of government is important in providing a sufficient and prevalent information and technology infrastructure across the district particularly in the area of south east Kalimantan. Government is expected to provide a supportive and reliable solution to reduce such barriers for SME's owner while creating an ease access of information for the society. The prevalent IT infrastructure on the other side is also able to give greater open access information to the society that may inspire the society intention to create a new small business. After all, when the IT infrastructure has met an equitable development across the province, the next step was to disseminate the use of technology for business and logistics use, particularly in the SME's area. 
The limitation of this study was the small amount of respondent and too specific SME's industry that may reduce the results generality across industry. The future studies are expected to use 7 Likert scale or semantic differential to better understand the respondent answer.

\section{Conclusion}

This research investigates the potential adoption of social commerce by small and medium enterprises in south east Kalimantan. In present studies, authors have used the unified theory of acceptance and use of technology (UTATUT). The constructs involved in this study was performance expectancy, entrepreneurial expectancy, social factor, facilitating condition and attitude towards smart meter. This model proposed to understand the potential adoption of social commerce in south east Kalimantan particularly on Sasirangan SME's. According to the model assessment, the largest effect was shown by social factor which means, the current social environment near the SME's were already use social media as one of daily activity. The indirect effect indicates the potential adoption has largely affected by the social factor mediated by the attitude towards the social commerce. Since the social environment near the SME's has acknowledged the social media as one of daily activity, it create such believe in the society that able to changes the perception/attitude towards social commerce thus create a positive effect to adopt social commerce for their business. However, there is on non-significant relation between the facilitating condition to attitude towards social commerce. This condition happened due to the equitable IT infrastructure development around SME's location.

The limitation of this study was the small amount of respondent and too specific SME's industry that may reduce the results generality across industry. The future studies are expected to use 7 Likert scale or semantic differential to better understand the respondent answer.

\section{Acknowledgments}

This works was supported by collaboration between Department of Research and Community Service, UNISKA and Directorate of Research and Community Service, Ministry of Research and Higher Education (DRPM RISTEK-DIKTI). A higher gratitude was given to the research enumerator for relentless support during data collection, processing up to the report organization.

\section{References}

[1] Hajli, M. (2013) A research framework for social commerce adoption. Inf. Manag. Comput. Secur. 21(3), 144-154. 
[2] Hajli, N. (2015) Social commerce constructs and consumer's intention to buy. Int. J. Inf. Manage. 35(2), 183-191.

[3] Hajli, N. \& Lin, X. (2016) Exploring the Security of Information Sharing on Social Networking Sites: The Role of Perceived Control of Information. J. Bus. Ethics. 133(1), 111123.

[4] Kim, S. \& Park, H. (2013). Effects of various characteristics of social commerce (scommerce) on consumers' trust and trust performance. Int. J. Inf. Manage. 33(2), 318-332.

[5] Hargadon, A. B. \& Bechky, B. A. (2006). When Collections of Creatives Become Creative Collectives: A Field Study of Problem Solving at Work. Organ. Sci. 17(4), 484-500.

[6] Kim, S. \& Park, H. (2013). Effects of various characteristics of social commerce (scommerce) on consumers' trust and trust performance. Int. J. Inf. Manage, 33(2), 318-332.

[7] Hoelzel, M. (2004). Social-Media Advertising: The Rush Into Social Is On, Led By Spending On Mobile And Programmatic/Business Insider India. Retrieved Jul 16, 2018, from: https://www.businessinsider.in/SOCIAL-MEDIA-ADVERTISING-The-Rush-Into-Social-IsOn-Led-By-Spending-On-Mobile-And-Programmatic/articleshow/43355757.cms

[8] Parrott, G., Azam Roomi, M. \& Holliman, D. (2010). An analysis of marketing programmes adopted by regional small and medium- sized enterprises. J. Small Bus. Enterp. Dev. 17(2), 184-203.

[9] Rakićević, J., Jakšić, M. L. J. \& Jovanović, M. (2018). Measuring the Potential for Technology Entrepreneurship Development: Serbian Cas. Manag. J. Sustain. Bus. Manag. Solut. Emerg. Econ. 2(23), 13-25.

[10] Venkatesh, V., Davis, F. D., Smith, R. H. \& Walton, S. M. (2000). A Theoretical Extension of the Technology Acceptance Model: Four Longitudinal Field Studies. Source Manag. Sci. 46(2), 186-204.

[11] Venkatesh, V., Morris, M. G., Davis, G. B. \& Davis, F. D. (2003). User Acceptance of Information Technology: Toward a Unified View. MIS Q. 27(3), 425.

[12] Hajli, M. \& Khani, F. (2013). Establishing trust in social commerce through social word of mouth. Int. J. Inf. Sci. Manag. 11(Spl.Iss), 39-53.

[13] Hajli, M. N. (2014). A study of the impact of social media on consumers. Int. J. Mark. Res. $56(3)$. 
[14] Abu, F. B. (2016). A Study on Adoption of Technology in SMEs Food Industry: UTAUT Model. Malaysia: Universiti Teknologi Malaysia.

[15] Hakim, M. M. \& Nurkamid, M. (2017). Model Adopsi UKM Di Kudus Terhadap ECommerce. Simetris J. Tek. Mesin, Elektro dan Ilmu Komput. 8(1). 339.

[16] Saifudin, R. Nirmala, D. \& Janie, A. (2014). Permodelan 'UTAUT' Pada UMKM Handycraft Binaan Bank Jateng. Semin. Nas. DAN CALL Pap. UNIBA, 1, 69-78.

[17] Khristianto, W., Kalnadi, D. \& Lestari, B. (2017). Analysis of Acceptance and Intention to Use Technology Among Micro Small and Medium Enterprises: Using UTAUT Model.

[18] Pavlou, P. A. (2003). Consumer Acceptance of Electronic Commerce: Integrating Trust and Risk with the Technology Acceptance Model. Int. J. Electron. Commer./Spring, 7(3), 69-103.

[19] Montreal, H. \& Takane, Y. (2004). Generalized Structured Component Analysis Heungsun Hwang.

[20] Jung, K., Takane, Y., Hwang, H. \& Woodward, T. S. (2012). Dynamic GSCA (Generalized Structured Component Analysis) with Applications to the Analysis of Effective Connectivity in Functional Neuroimaging Data. Psychometrika, 77(4), 827-848.

[21] Hee Jung, K. (2011). Dynamic GSCA (Generalized Structured Component Analysis): A Structural Equation Model for Analyzing Effective Connectivity in Functional Neuroimaging. 